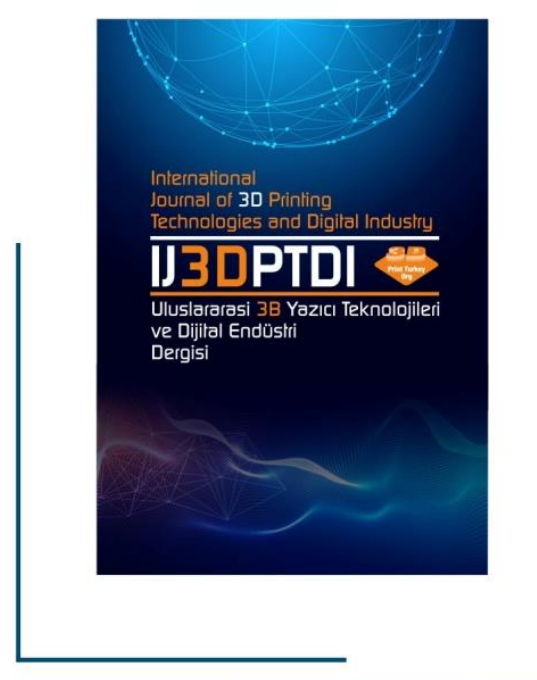

ULUSLARARASI 3B YAZICI TEKNOLOJILERI

VE DIJITAL ENDÜSTRI DERGISI

INTERNATIONAL JOURNAL QF 3D PRINTING TECHNOLOGIES AND DIGITAL INDUSTRY

I55N:2602-3350 [Online]

URL: https://dergipark.org.tr/ij3dptdi

\title{
STRUCTURAL \& DYNAMIC ANALYSES AND SIMULATION OF MOBILE TRANSPORTATION ROBOT
}

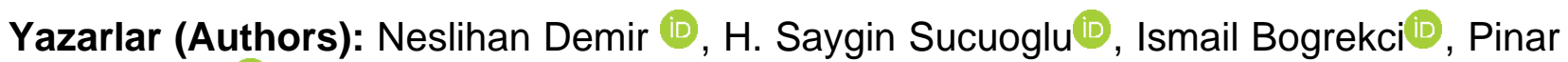
Demircioglu*(iD)

Bu makaleye şu şekilde atıfta bulunabilirsiniz (To cite to this article): Demir N., Sucuoglu H.S., Bogrekci I., Demircioglu P., "Structural \& Dynamic Analyses And Simulation Of Mobile Transportation Robot" Int. J. of 3D Printing Tech. Dig. Ind., 5(3): 587595, (2021). 


\title{
STRUCTURAL \& DYNAMIC ANALYSES AND SIMULATION OF MOBILE TRANSPORTATION ROBOT
}

\author{
Neslihan Demir ${ }^{\mathrm{a}, \mathrm{b}}$ iD, H. Saygin Sucuoglu ${ }^{\mathrm{i}}$, Ismail Bogrekci ${ }^{\mathrm{a}}$ iD, Pinar Demircioglu ${ }^{\mathrm{a}^{*} \text { iD }}$ \\ a Aydin Adnan Menderes University, Faculty of Engineering, Mechanical Engineering Department, TURKEY \\ ${ }^{\mathrm{b}}$ PhD Student of YOK 100-2000 on Robotic Technologies, TURKEY \\ * Corresponding Author: pinar.demircioglu@adu.edu.tr
}

(Received: 08.06.2021; Revised: 13.08.2021; Accepted: 10.12.2021)

\begin{abstract}
In this study, structural and dynamic analyses were applied to the mobile transportation robot to find the structural strength and to calculate the power and torque requirements. The mobile transportation robot was designed using CAD (Computer Aided Design) software as two modules; mecanum wheeled locomotion module and robotic arm module, respectively. The analyses were carried on the CAE (Computer Aided Engineering) Software using the static structural and rigid body dynamics tools. In the structural analysis, the weight of the robot and the additional load $(98.1 \mathrm{~N})$ were applied to the body of the robot. The material of the robot body was selected as Aluminum $6061 \mathrm{O}$ sheet metal. In the dynamic analysis, the operation environment and conditions were simulated in the CAE software. The structural analysis results showed that the factor of safety value was obtained as 10.282 under applied loads and this value indicates that the chassis of mobile transportation robot is supposed to carry loads reaching up to $30 \mathrm{~kg}$ without any functional and mechanical problem. Furthermore, from the dynamic analysis, the total torque requirement of the mobile robot was about $16.56 \mathrm{Nm}$.
\end{abstract}

Keywords: Dynamic Analysis. Finite Element Analysis. Mecanum Wheel. Mobile Robot. Structural Analysis.

\section{INTRODUCTION}

The Fourth Industrial Revolution (Industry 4.0) has incorporated into outstanding technologies as Mobile Robotic Systems for contemporary manufacturing companies. Usage of mobile robotic systems has been increasing with their intelligence and autonomous capabilities. In general terms, autonomous mobile robots are a combination of mechanisms as locomotion, cognition, perception, and navigation. Kinematics, Dynamics, and Control Theory are assigned to clear up locomotion mechanism problems. Perception comprises tools as sensor, computer vision and signal processing. In terms of cognition, data as inputs obtaining from sensors provides transformation for achieving the tasks of mobile robots according to the control system scheme. Artificial Intelligence, path planning algorithms are required for solving navigation problems [1].

Autonomous mobile robotic systems have been commonly seen in two types as legged and wheeled mobile robot. Both have advantages and disadvantages. Wheeled mobile robots have more simple mechanism, lower weight, easier to control and faster than legged ones [2]. The legged mobile robots have better mobility and maneuverability in soft and uneven grounds [3]. However, when it comes to ability of carrying heavy loads, moving faster, and consuming efficiently power, wheeled mobile robots are more practical and functional [4,5]. Thus, wheeled mobile robots are commonly chosen and used for applications of manufacturing facilities.

Wheeled mobile robots can be seen with different wheel types and drive mechanisms in academic and commercial implementations. The omnidirectional mobility, which is one of the drive mechanisms for mobile robots, is defined as having motion capability to move instantly in all directions from any configuration. Omnidirectional vehicles are capable to translate in $\mathrm{x}$ and $\mathrm{y}$ directions and rotate about its gravity center [6]. Mecanum wheel is one of the special type wheels for providing omnidirectional 
mobility, which was found by Bengt Ilon in 1975. There are varied numbered outer rollers around sphere of the wheel and these rollers are formed with different materials as metallic, plastic, harden rubber, delrin etc. They are located around central axis of the wheel with $45^{\circ}[7,8]$.

A wide variety of approach has been improving on mobile robot which are used for transporting materials, parts etc. at industrial environment. Such as Jang et. al [9] asserted a self-collision avoidance algorithm between mobile robot and manipulator with using Distance Buffer Border concept. Ramasubramanian et. al. [10] focused on an approach on mobile robotic to fulfill simultaneously handling and transporting parts considering human operator and mobile robot interaction. This mobile robot has been performing handling operations with a robotic arm and gripper. They compared the fully automated robotic solutions to operation with human operator and mobile robot interaction. Oltean [11] proposed a low cost four wheeled mobile robot platform with one degree of freedom robotic arm for lifting and transportation. However, the mobile robot was able to follow a predetermined line while operation. Sichkar et. al. [12] studied a solution for stabilization of mobile robot during transportation by using machine learning technologies. Lee et. al. [13] presented an approach for picking and transportation of warehouse orders by minimizing the deliver time of items from picking list to packing station.

Mobile Transportation Robot was designed on a basis of possessing mecanum wheel and omnidirectional drive mechanism. Four wheels were opted for becoming more stable as are seen in transport, logistics, food industry etc. In this paper, structural and dynamic analyses were conducted to obtain stress, deformation, factor of safety values and determine behaviors depending on applied forces on the mobile robot.

\section{MOBILE TRANSPORTATION ROBOT STRUCTURE}

Mobile Transportation Robot was design using parametric solid modelling technique on SolidWorks 2021 as a computer aided design (CAD) program. Mainly, mobile transportation robot consists of two modules, mecanum wheeled locomotion module and robotic arm module, respectively (Figure 1).

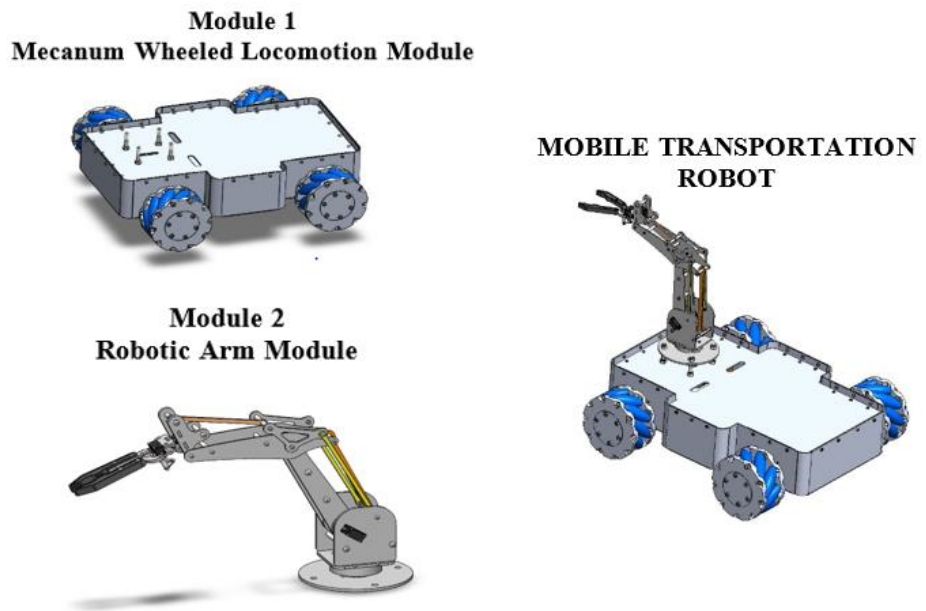

Figure 1. Modules of Mobile Transportation Robot

The mecanum wheeled locomotion module was designed to achieve objectives as performing motion consisting of forward, backward, skipping \& sliding on the ground of a manufacturing plant, carrying semi-finished products, parts, tools with specific dimensions (Figure 2). It comprised of four mecanum wheels, required equipment ensuring mobility, chassis etc. All links have been implemented for locomotion to provide mobility and maneuverability. 


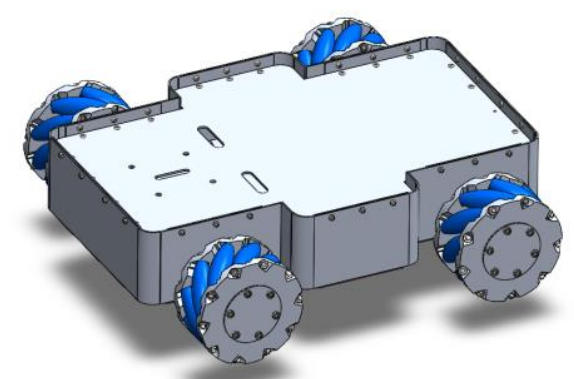

Figure 2. Mecanum Wheeled Locomotion Module of Mobile Transportation Robot.

The mobile robot is supposed to carry a maximum load of $30 \mathrm{~kg}$ as small semi-finished products, parts, tools between operation units and warehouse in an industrial environment. Thus, the maximum linear velocity is $2 \mathrm{~m} / \mathrm{s}$. The chassis of mobile robot was designed with dimensions $580 \mathrm{~mm}$ long and $400 \mathrm{~mm}$ wide considering the constraints on transportation of specific parts, environment condition, performing required objectives. The material of chassis would be aluminum 6061 sheet metal with $2 \mathrm{~mm}$ thickness. Four mecanum wheels were approved to use for mobility. The detailed dimensions of chassis are given in Table 1 and symbols of related dimensions are shown in Figure 3.
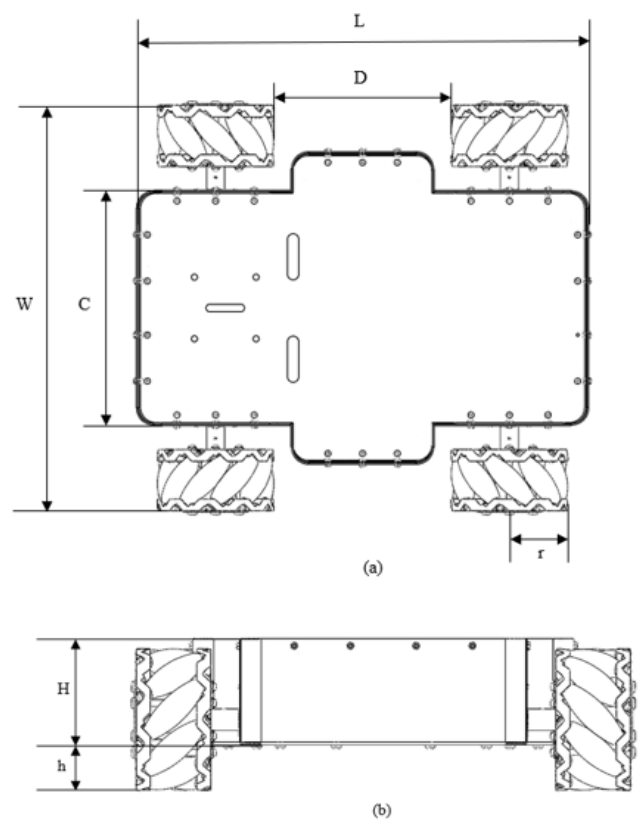

Figure 3. Dimensions of chassis with mecanum wheels (a) Top view (b) Front view.

Table 1. Dimensions and explanation for platform chassis with mecanum wheels.

\begin{tabular}{ccc}
\hline \hline Symbol & Value (mm) & Explanation \\
L & 580 & Chassis Length \\
W & 400 & Chassis Width \\
$\mathrm{C}$ & 300 & Vertical Distance Between Right \& Left Wheel \\
$\mathrm{D}$ & 230 & Vertical Distance Between Front \& Back Wheel \\
$\mathrm{r}$ & 75 & Radius of Wheel \\
$\mathrm{H}$ & 113 & Chassis Height \\
$\mathrm{h}$ & 50 & Ground Clearance of Chassis \\
\hline \hline
\end{tabular}

The design was planned and performed considering that material of chassis would be Aluminum $6061 \mathrm{O}$ sheet metal with $2 \mathrm{~mm}$ thickness. Mechanical properties are presented in Table 2 for Aluminum $6061 \mathrm{O}$ sheet metal. 
Table 2. Mechanical properties of Aluminum 6061 O sheet metal [14].

\begin{tabular}{cc}
\hline \hline Property & Value (Metric) \\
\hline \hline Density & $2.70 \mathrm{~g} / \mathrm{cm}^{3}$ \\
Young Modulus & $68.9 \mathrm{GPa}$ \\
Shear Modulus & $26 \mathrm{GPa}$ \\
Yield Strength & $276 \mathrm{MPa}$ \\
Ultimate Tensile Strength & $310 \mathrm{MPa}$ \\
Shear Strength & $207 \mathrm{MPa}$ \\
Fatigue Strength & $96.5 \mathrm{MPa}$ \\
\hline \hline
\end{tabular}

Mobile Transportation Robot has four fixed mecanum wheels to perform locomotion. Mecanum wheels were designed on consideration of their higher weight capacity and smooth motion. An individual mecanum wheel has $150 \mathrm{~mm}$ diameter, and 10 rollers, presented in Figure 4. Each mecanum wheel was powered by high torque DC motors. At mecanum wheeled locomotion module, wheels should be in a position as $X$ pattern of 1-4 numbered wheels and 2-3 numbered wheels, according for fulfilling the mecanum drive mechanism as in Figure 5 [15]. Otherwise, wheels cannot operate properly. Directions of wheels can be assigned to wheel rotations.

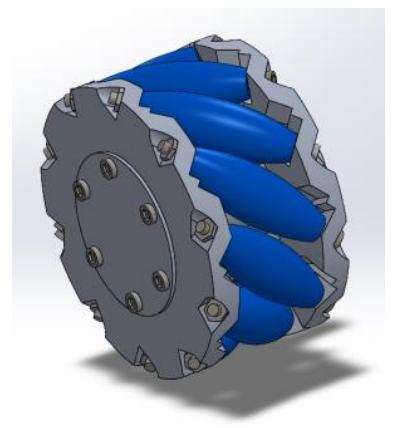

Figure 4. Mecanum Wheel of Mobile Transportation Robot.

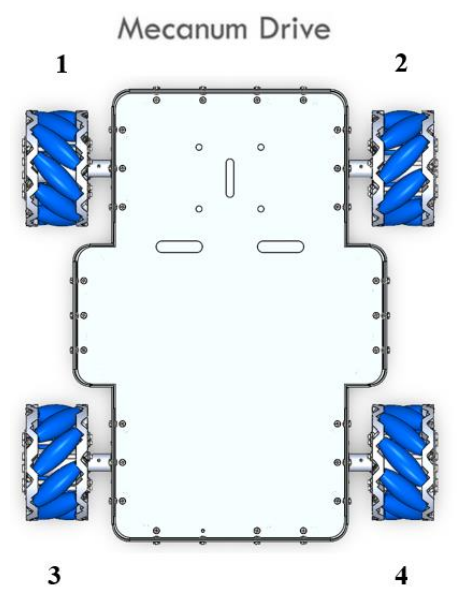

Figure 5. Mecanum drive wheels position on top view of Mecanum Wheeled Locomotion module.

\section{STRUCTURAL AND DYNAMICAL ANALYSES}

Mobile transportation robot is supposed to operate under the specific loads; therefore, the tasks are expected from the design of it. At this point, the structural analysis of mobile transportation robot provides significantly to determine mechanical characteristics that encounters conditions related to the worst scenario in the working environment. So, the results of structural analysis are able to induce 3D solid design [16].

The mecanum wheeled locomotion module has the components which require power sources to perform mobility and the other tasks. It was needed to ensure that Mobile Transportation Robot can work in all situations. The analyses were gone through with the situations at the worst scenario. It was assumed that 
the worst scenario was comprised of the robotic system working with maximum payload. If the Mobile Transportation Robot overcomes situations with the worst scenario, it can operate with the other situations. Generating the worst scenario should start with determine the transmitted loads applied to Mecanum Wheeled Locomotion Module components.

The mecanum wheeled locomotion module of mobile robot structure was analyzed on static and dynamic situations which were carried out by Static Structural Module and Rigid Body Dynamics Module on via Ansys 2021 Workbench. Analyses were conducted in terms of determination and verification the specific mechanic characteristics. These mechanic characteristics have been providing for robotic structure to enable design specification in static situations as working in progress.

\subsection{Structural Analysis}

The main purpose of Mobile Transportation Robot is to carry semi-finished products, parts, tools with specific dimensions below the chassis of mobile robot. In consideration of this purpose, there would be mechanical situations such as stress, deformation caused by applied loads and forces. For completing design process, the structural analysis has assigned to control and validate mechanical situations of Mobile Transportation Robot.

CAE analysis was conducted via ANSYS Workbench 2021. The finite element analysis of mobile robot chassis was composed of 361,617 nodes with 183,192 elements. The element order was quadratic and average element size was $5 \mathrm{~mm}$. It was assumed that the maximum applied load was enforced on top of the chassis. The applied force on the chassis was accepted as $300 \mathrm{~N}$ and gravitational force on downwards of y direction as in Figure 6 . The total weight of mecanum wheeled locomotion module was approximately $12 \mathrm{~kg}$.

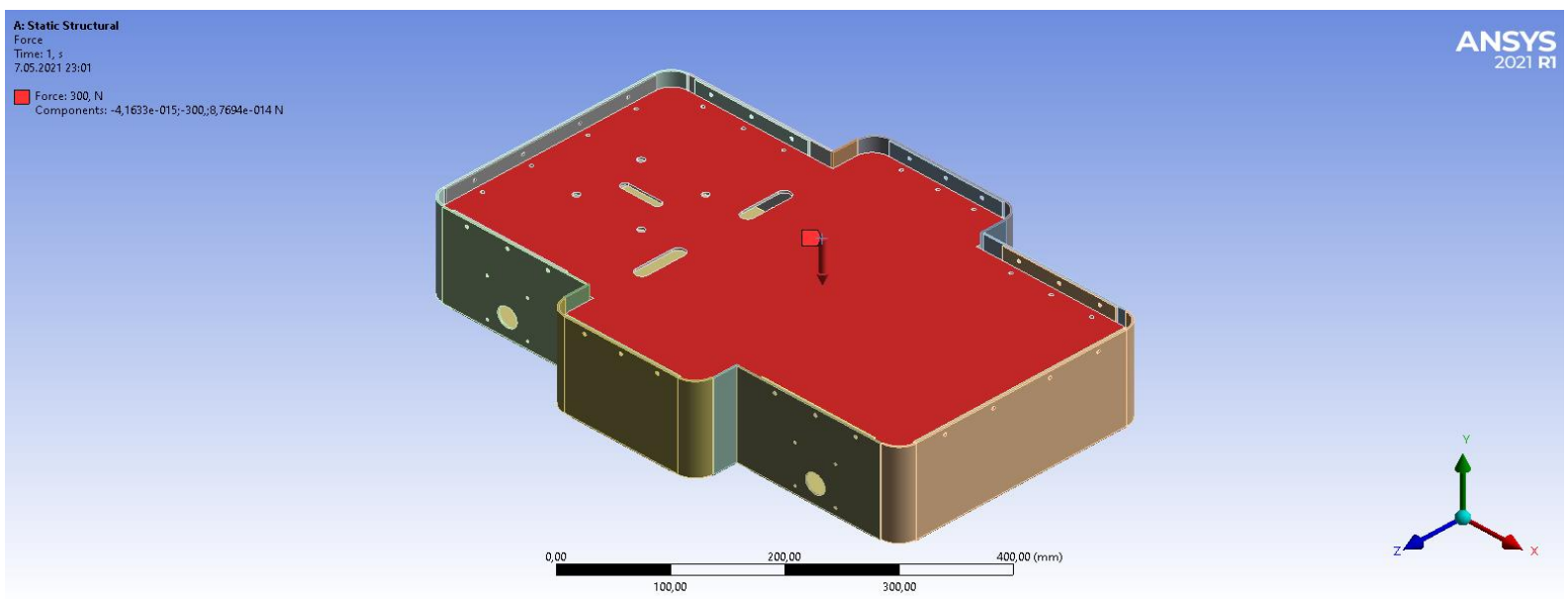

Figure 6. Applied force on chassis of Mecanum Wheeled Locomotion Module

According to static structural analysis, it was obtained $26.844 \mathrm{MPa}$ as maximum equivalent stress and $0.2333 \mathrm{~mm}$ as total deformation, when $300 \mathrm{~N}$ was applied on the top part of chassis. Also, the factor of safety was found as 10.282. they are presented in Figure 7, Figure 8 and Figure 9. 

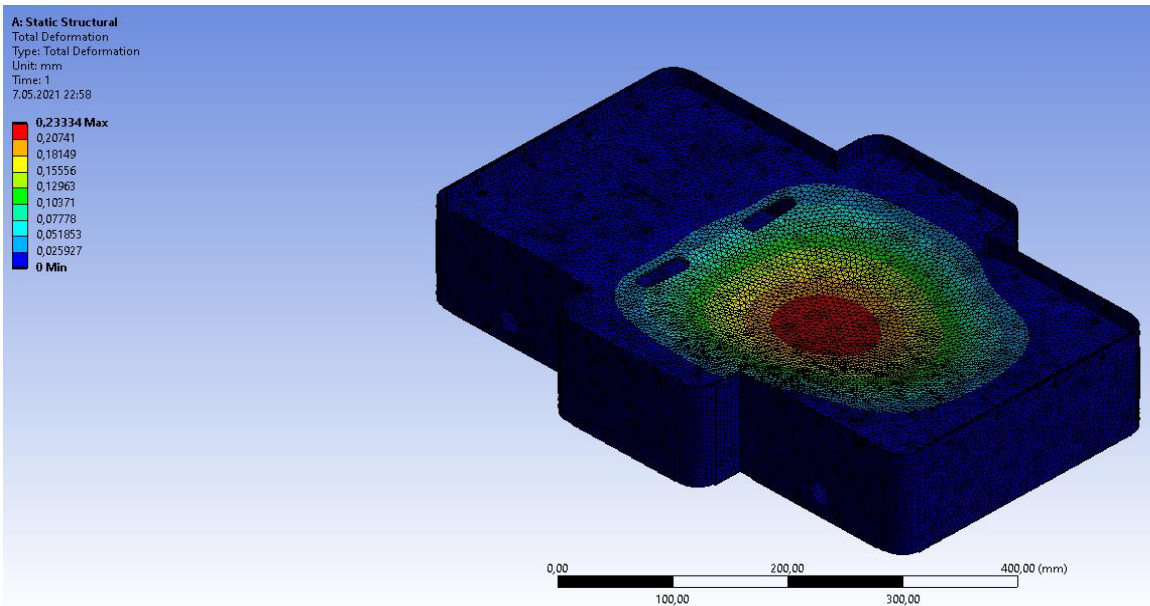

Figure 7. Total deformation of Mobile Transportation Robot.

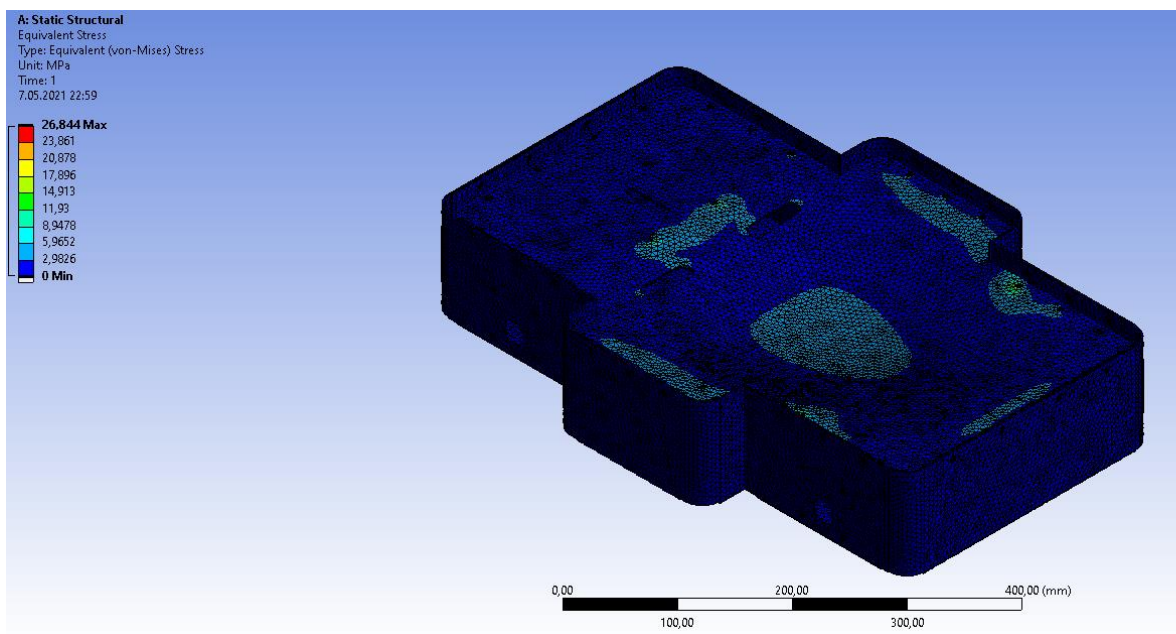

$\underset{2021 \mathrm{PT}}{\text { ANSYS }}$

Figure 8. Equivalent Stress of Mobile Transportation Robot.

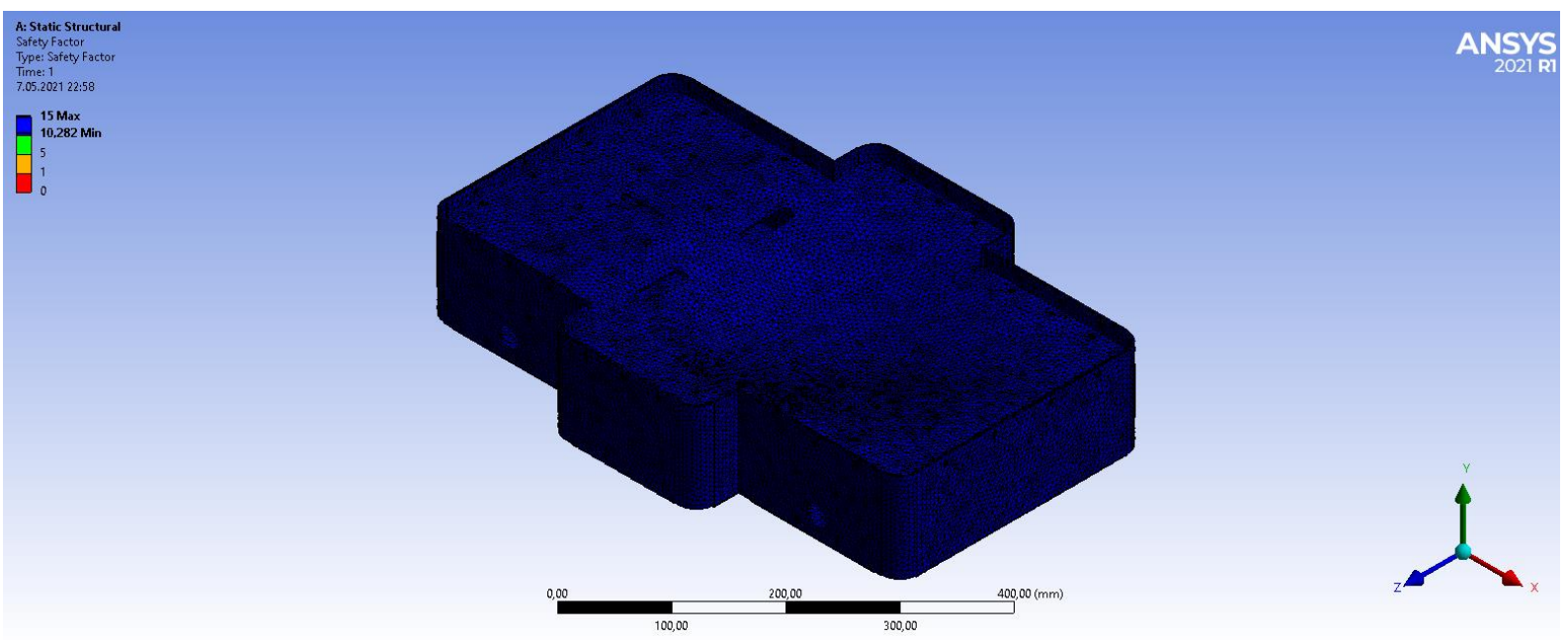

Figure 9. The factor of safety for Mobile Transportation Robot.

\subsection{Dynamic Analysis}

The mecanum wheeled locomotion module has the components which require power sources to perform mobility and the other tasks. It was needed to ensure that Mobile Transportation Robot can work in all situations. The analytical and numerical analyses were gone through with the situations at the worst scenario. It was assumed that the worst scenario was comprised of the robotic system working with maximum payload. If the Mobile Transportation Robot overcomes situations with the worst scenario, it 
can operate with the other situations. Generating the worst scenario should start with determine the transmitted loads applied to Mecanum Wheeled Locomotion Module components.

There were a couple of acceptance for performing analyses. According to the predetermined scenario, slope angle of Mobil Transportation robot was maximum 20 degree, is presented in Figure 4 and it was accepted that there would be no acceleration. Also, the maximum speed of vehicle would be reached to $2 \mathrm{~m} / \mathrm{s}(7.2 \mathrm{~km} / \mathrm{h})$.

The analytical and numerical calculations were conducted on MATLAB 2020 and ANSYS 2021R1. The aim of analyses was to obtain required torque, rpm values according to linear and angular velocity. MATLAB codes were written on the script to calculate w (angular velocity - rad/s), power (W) and rpm (revolutions per minute) in the light of theoretical background. According to every $0.25 \mathrm{~m} / \mathrm{s}$ change of linear velocity, rpm and power values were obtained and are shown in Table 3. According to MATLAB results, the total power requirement was obtained as $170.468 \mathrm{~W}$ att when the robot reached $2 \mathrm{~m} / \mathrm{s}$ driven speed.

Table 3. Analytical calculation results on MATLAB

\begin{tabular}{|c|c|c|c|}
\hline \multicolumn{4}{|c|}{ Required RPM } \\
\hline $\mathrm{V}(\mathrm{m} / \mathrm{s})$ & $\mathrm{w}(\mathrm{rad} / \mathrm{s})$ & RPM & $\mathbf{P}(\boldsymbol{W})$ \\
\hline 0.00 & 0.00 & 0.000 & 0.000 \\
\hline 0.25 & 3.33 & 31.371 & 21.309 \\
\hline 0.50 & 6.67 & 63.662 & 42.617 \\
\hline 0.75 & 10.00 & 95.493 & 63.926 \\
\hline 1.00 & 13.33 & 127.324 & 85.234 \\
\hline 1.25 & 16.67 & 159.155 & 106.543 \\
\hline 1.50 & 20.00 & 190.986 & 127.851 \\
\hline 1.75 & 23.33 & 222.817 & 149.160 \\
\hline 2.00 & 26.67 & 254.648 & 170.468 \\
\hline
\end{tabular}

The rigid body dynamics can be used in coping with calculation the motion of robotic geometries without deformation [17]. Rigid Body Dynamics module on Ansys Workbench has been used for numerical analysis and provide computations to find torque, velocity, power etc. requirement without any change on the structure of body [18].

The analysis environment is shown in Figure 10. The same acceptances were used on the numerical analyses. The objective of numerical analysis was to find torque requirement of Mobile Transportation Robot. Considering maximum linear velocity would be $2 \mathrm{~m} / \mathrm{s}$, the torque requirement per wheel was found as $3.8 \mathrm{Nm}$ and the total torque requirement was $15.2 \mathrm{Nm}$.

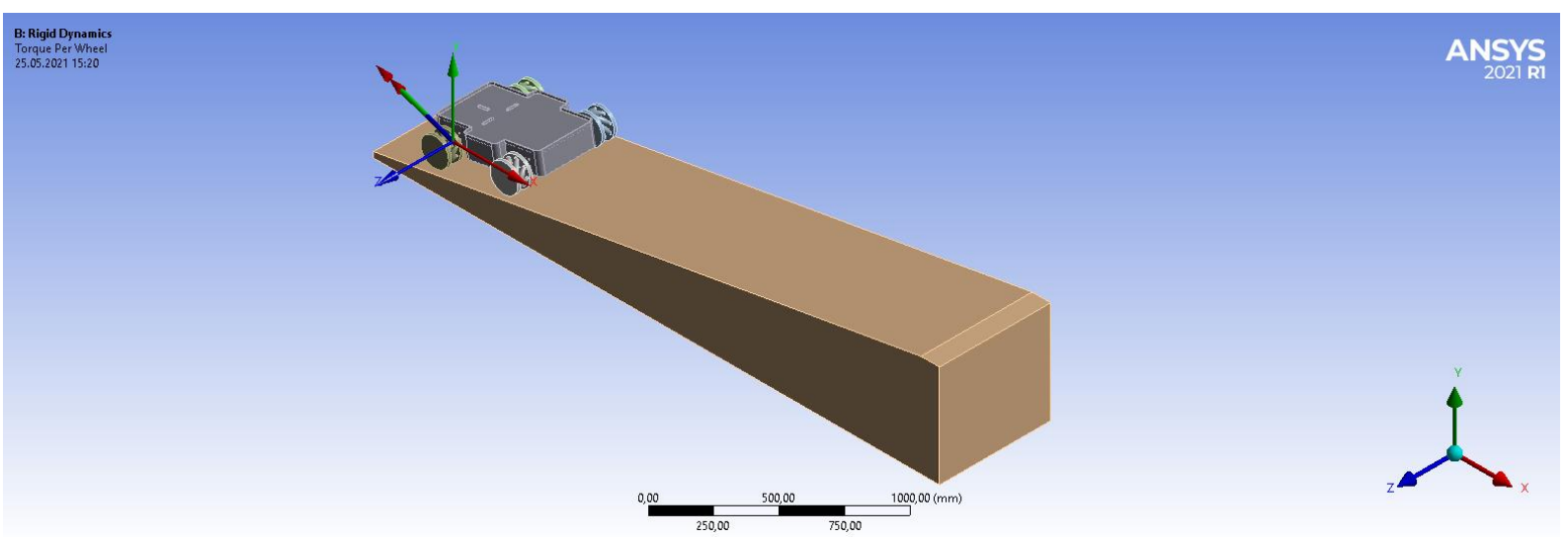

Figure 10. Rigid body dynamic analysis of Mecanum Wheeled Locomotion Module. 


\section{CONCLUSION}

In this study, structural and dynamic analyses were applied to the mobile transportation robot to find the structural strength and to calculate the power and torque requirements. The structural strength of the robot was checked under the operational loads. The torque and rotational velocity requirements of the robot were calculated using the CAE tools and numerical calculations to select the proper motors. The occurred stresses and factor of safety values of the robotic body were calculated as $27 \mathrm{MPa}$ and 10 respectively. The torque requirement of each motor was found as $3.8 \mathrm{Nm}$ per each motor. From these results it can be concluded that the chassis of mobile transportation robot is supposed to carry applied loads reaching up to $30 \mathrm{~kg}$ without any functional and mechanical problem. Besides that, the proper motors were selected using these analyses and calculations.

\section{REFERENCES}

1. Siegwart, R., Nourbakhsh, I., R. "Introduction to autonomous mobile robots" England: A Bradford Book, The MIT Press Cambridge, Massachusetts, London, 2004.

2. Silva, M. F., Machado, J. A. T., "A Historical Perspective of Legged Robots", Journal of Vibration and Control, Vol. 13, Pages 1447-1486, 2007.

3. Raibert, M. H., "Legged robots", Commun. ACM, Vol. 29, Pages 499-514, 1986.

4. Rubio, F., Valero, F., Llopis-Albert, C., "A review of mobile robots: Concepts, methods, theoretical framework, and applications", International Journal of Advanced Robotic Systems, Vol. 16, Issue 2, Pages 1-22, 2019.

5. Kanjanawanishkul, K., "Omnidirectional wheeled mobile robots: wheel types and practical applications", Int. J. Advanced Mechatronic Systems, Vol. 6, Issue 6, Pages 289-302, 2015.

6. Doroftei, I., Grosu, V., Spinu, V., "Omnidirectional Mobile Robot - Design and Implementation", Bioinspiration and Robotics: Walking and Climbing Robots, Pages 511-528, Vienna, Austria, 2007.

7. Muthiah, P., Akilan, S. A. S., Sugumar, A., Sasidhar, S., Vishnuram, N. S. "Design of Single Drive Transmission System for Mecanum Wheels" International Conference on Mechanical, Electronics and Computer Engineering: ICMECE 2020, AIP Conference Proceedings, Vol. 2271, Issue 1, Kancheepuram, India, 2020.

8. Adascaliţei, F., Doroftei, I., "Practical Applications for Mobile Robots Based on Mecanum Wheels - A Systematic Survey" Proceedings of International Conference Innovations, Recent Trends and Challenges, In Mechatronics, Mechanical Engineering and New High-Tech Products Development - MECAHITECH'11, Vol. 3, Pages 112-123, Bucharest, Romania, 2011.

9. Jang, K., Kim, S., Park, J., "Reactive Self-Collision Avoidance for a Differentially Driven Mobile Manipulator", Sensors, Vol. 21, Issue 3, Pages 890-911, 2021.

10. Ramasubramanian, A. K., Papakostas, N., "Operator - mobile robot collaboration for synchronized part movement", Procedia CIRP, Vol. 97, Pages. 217-223, 2020.

11. Oltean, S. E., "Mobile Robot Platform with Arduino Uno and Raspberry Pi for Autonomous Navigation", Procedia Manufacturing, Vol. 32, Pages 572-577, 2019.

12. Sichkar, D. P., Bezumnov, N., Voronov, V. I., Voronova, L. I., Dankovtsev, V. I., "Moving Elements of Mobile Robots Stabilization Modelling", Systems of Signals Generating and Processing in the Field of on-Board Communications, Moscow, Russia, 2019.

13. Lee, H. Y., Murray, C. C., "Robotics in order picking: evaluating warehouse layouts for pick, place, and transport vehicle routing systems", International Journal of Production Research, Vol. 27, Issue 18, Pages 5821-5841, 2018.

14. Cavallo, C., "All About 6061 Aluminum (Properties, Strength and Uses)", https://www.thomasnet.com/articles/metals-metal-products/6061-aluminum/, May 04, 2021. 
15. Tayfur, D. T., "Design and Comparison of Controller Performance on Four Mecanum Wheeled Mobile Robot" Master Thesis, Istanbul Technical University Graduate School of Science Engineering and Technology Department of Mechanical Engineering System Dynamics \& Control Program, Istanbul, Turkey, 2016.

16. Habibian, A., Darandaashi, Y. A., Fesharakifard, R., Phadi, A., Ghafarirad, H. "Structural and Dynamic Analysis of a Wheeled Mobile Robot with different Wheel Configurations" 2017 5th RSI International Conference on Robotics and Mechatronics (ICRoM), Pages 527-533, Tehran, Iran, 2017.

17. Ettlin, A., "Rigid Body Dynamics Simulation for Robot Motion Planning" PhD thesis, Ecole Ploytecnique Federale de Lausanne University Faculty of Engineering Sciences and Techniques, Ecublens, Switzerland, 2006.

18. Sucuoglu, S., Bogrekci, I., Gultekin, A., Demircioglu, P., "Design, Analysis and Development Mobile Robot with Flip-Flop Motion Ability", International Federation of Automatic Control (IFAC), Vol. 51, Issue 30, Pages 436-440, 2018. 